\title{
Decomposing culture: An analysis of gender, language, and labor supply in the household
}

\author{
Victor Gay* Daniel L. Hicks ${ }^{\dagger} \quad$ Estefania Santacreu-Vasut ${ }^{\ddagger}$ \\ Amir Shoham ${ }^{\S}$
}

\begin{abstract}
Despite broad progress in closing many dimensions of the gender gap around the globe, recent research has shown that traditional gender roles can still exert a large influence on female labor force participation, even in developed economies. This paper empirically analyzes the role of culture in determining the labor market engagement of women within the context of collective models of household decision making. In particular, we use the epidemiological approach to study the relationship between gender in language and labor market participation among married female immigrants to the U.S. We show that the presence of gender in language can act as a marker for culturally acquired gender roles and that these roles are important determinants of household labor allocations. Female immigrants who speak a language with sex-based grammatical rules exhibit lower labor force participation, hours worked, and weeks worked. Our strategy of isolating one component of culture reveals that roughly two thirds of this relationship can be explained by correlated cultural factors, including the role of bargaining power in the household and the impact of ethnic enclaves, and that at most one third is potentially explained by language having a causal impact.
\end{abstract}

Keywords Language, Gender gap, Bargaining power in the household, Labor force participation, Immigrants

JEL classification F22, J16, Z13

\footnotetext{
${ }^{*}$ Department of Economics, The University of Chicago, 5757 S. University Ave, Chicago, IL, 60637, U.S.A.

$\dagger$ Department of Economics, University of Oklahoma, 308 Cate Center Drive, Norman, OK, 73019, U.S.A.

${ }^{\ddagger}$ Corresponding Author: Department of Economics, ESSEC Business School and THEMA, 3 Avenue Bernard Hirsch, 95021

Cergy-Pontoise, France (santacreuvasut@essec.edu)

$\S$ Temple University and COMAS, 1801 N. Broad St, Philadelphia, PA, 19122, U.S.A.
} 


\section{Introduction}

The labor force participation rate of married women has increased spectacularly during the second half of the 20th century, both in the U.S. and around the world (Goldin 2014). Nevertheless, wide differences across countries remain, with the gender gap closing faster in some countries than others, and a number of developing nations, such as India, lagging behind (Field et al. 2016). Among the factors used to explain these differences, the role of cultural norms has been shown to play a crucial role (Fernández 2007, Fernández \& Fogli 2009, Alesina et al. 2013, Farré \& Vella 2013, Fernández 2013). In particular, scholars have begun employing the epidemiological approach to distinguish the impact of cultural factors from that of other institutional forces (Fernández \& Fogli 2009, Fernández 2011) 1

When analyzing married couples, both individual and spousal culture are thought to play an important role in explaining labor market decisions. Early collective models of labor supply emphasize the importance of taking into account the distribution of bargaining power within the household (Chiappori et al. 2002, Blundell et al. 2007). Recently however, these models have been extended to investigate whether their main predictions depend not only on bargaining power, but also on the surrounding cultural context (Oreffice 2014) as well as on social and institutional constraints related to traditional gender roles (Field et al. 2016). These norms may influence women to allocate more labor to household production relative to the formal market at either the intensive or extensive margin.

This paper studies the impact of gender roles on the labor force participation of married female immigrants in the U.S. within a collective labor supply framework. We explore culturally acquired gender roles as those embodied by the presence of grammatical gender in language spoken. Recent work has documented correlations between linguistic structure and individual behavior (Lupyan \& Dale 2010, Chen 2013, Ladd et al. 2015) with the presence and intensity of gender in grammatical structures correlating with gender gaps in compensation and promotions, division of household labor, educational attainment, and political empowerment (Givati \& Troiano 2012, Santacreu-Vasut et al. 2013, Santacreu-Vasut et al. 2014, Hicks et al. 2015, Mavisakalyan 2015, van der Velde et al. 2015, Davis \& Reynolds 2016).

The mechanisms underlying these associations are largely unresolved. Perhaps the most compelling question, whether language may causally influence behavior, remains a subject of debate $2^{2}$ Linguistic correlations could reflect historically acquired cultural norms of behavior that became codified in language or language itself could represent an institutional force, influencing and perpetuating a set of behaviors.

From a methodological point of view, because language is observed at the individual level, it is possible to isolate its effect from the influence of aggregate correlated historical, cultural, and biological forces. This is an exercise we undertake in this analysis following the epidemiological approach. Furthermore, because language acts a cultural marker for gender roles, we show that this barometer of norms allows us to examine

\footnotetext{
${ }^{1}$ Gay et al. (2016) provides an in-depth discussion of the epidemiological approach in this context.

${ }^{2}$ Theoretically language structures could influence preference formation, information processing, categorization of social reality, and the salience of certain categories of words. These impacts could alter a speaker's decision making and behavior (Mavisakalyan \& Weber 2016).
} 
labor market predictions of the collective household model in the presence or absence of these cultural influences. This yields new insights regarding their relative influence.

To do this, we examine labor market outcomes for nearly half a million married female immigrants to the U.S. aged 25 to 49 in the American Community Surveys (ACS) between 2005 and 2015. In our analysis, we focus on married, foreign born individuals, who speak a language other than English in the home. With the assistance of linguists and drawing on information contained in the World Atlas of Linguistic Structures database (WALS), we assign to these speakers consistent measures of the presence and intensity of gender in the grammatical structure of their language.

There are several novel empirical advances to the approach taken in this paper. First, this analysis relies on a detailed set of microeconomic data which provides a rich set of covariates and substantial variation to control for many potential confounding factors. These include many of the individual, spousal, and household level variables analyzed in the past, as well as measures which may influence the decision to migrate in the country of origin and measures of the location to which the immigrant has moved. A second advantage is reliance on the epidemiological approach in this setting which helps ameliorate a fundamental problem of identification. By using a restrictive fixed effects strategy, including country fixed effects, we are able to capture a wide array of unobservable cultural forces and obtain identification using variation in language spoken from individuals of the same country of origin or ancestry.

The takeaways from this exercise are several. First, we show that married female immigrants speaking a language with sex-based distinctions in its grammar are less likely to participate in the labor market. This is true even after controlling for observable characteristics such as traditional household measures, husband characteristics, and bargaining power measures, as well as when controlling for a vast set of unobservable cultural forces through country of origin fixed effects 3 When we empirically decompose the relationship between gender in language and gendered behavior in this manner, it suggests that roughly two thirds of this relationship can be explained by correlated cultural factors, with about one third potentially explained by language having a causal impact.

Second, using language as a measure of culturally acquired gender roles allows us to speak to and test the role of bargaining power within the household relative to the impact of cultural norms. We demonstrate that both are important, and that their impacts are distinct from one another.

Third, focusing on language spoken allows to also study the behavior of female immigrants in both linguistically homogeneous and heterogeneous couples. We exploit linguistic heterogeneity within the household to show that the presence of gender in language has an association with a wife's behavior both when husbands and wives speak a gendered language, and when they speak languages with different structures. Our findings suggest that while there is an independent effect on a wife's behavior when she alone has a gender marked language, gender marking in the husbands language enhances this effect.

\footnotetext{
${ }^{3}$ One of the challenges of the literature on culture and economic behavior has been to measure culture. An advantage of using language over existing alternatives is that language is defined at the individual level and is not an outcome measure. It allows us to control for country of origin characteristics including time varying ones.
} 
Fourth, using language as a measure of gender roles but recognizing it as a network technology allows us to examine the role that ethnic enclaves play in influencing female labor force participation. In theory, enclaves may improve labor market outcomes by providing information about formal jobs and reducing social stigma on employment. At the same time, enclaves are likely to reinforce immigrant language usage and thus may enhance the impact of gender in language or provide isolation from U.S. norms. We present evidence implying that the latter effect is present, which suggests that the impact of language is stronger when it is shared with the surrounding community 4

Finally, and as part of our robustness checks, we also show that some forms of gender roles are not be present for unmarried women suggesting that they may be "dormant" when unmarried - the pressure to not work, to raise children, to provide household goods.

These findings speak to several literatures. Mavisakalyan \& Weber (2016) review of the nascent field of linguistic relativity and economics and point out that the mechanisms behind the associations between language and economic behavior remain largely unresolved. Despite the current study's ability to account for both time-invariant and time-variant country of origin factors in a more rigorous manner than previous analyses, the correlation between language and behavior remains significant and negative. This means that while we can demonstrate that most of this association can be explained by language as a cultural market for correlated gender norms, we cannot formally disprove that the behavioral channel may explain some of the remaining correlation (Roberts \& Winters 2013, Hicks et al. 2015, Roberts et al. 2015) 5

Our research also directly contributes to literature that investigates whether the impact of intra-household bargaining power on the labor supply depends on culture. In particular, our results imply that the standard prediction that the spouse with higher bargaining power will substitute labor for leisure due to an income effect as in Oreffice (2014) applies only to native born couples in the U.S., and to immigrant couples with gender roles similar to the U.S. Interestingly, our results confirm that in couples coming from countries classified as exhibiting strong traditional gender roles, the influence of bargaining power on household collective labor supply may be culturally dependent and that some of these standard predictions may not hold for these groups.

While Oreffice (2014) focuses on the intensive labor supply among couples where both spouses are working, we focus mainly on the extensive margin and how bargaining power influences female labor force participation. Field et al. (2016) study the extensive margin of the labor supply among married female in India and model the impact of bargaining power distribution within the household with social constraints related to traditional gender norms. Our findings complement these studies by empirically showing that the married female immigrants with stronger bargaining power are more likely to work, not less, and that the impact of bargaining power is reinforced when traditional gender roles are embodied in the language spoken.

This paper is structured as follows. Section 2 presents summary statistics for both the ACS and linguistic

\footnotetext{
${ }^{4}$ This result is not solely attributable to selection since it holds for women married prior to migration-sometimes referred to as "tied women".

${ }^{5}$ See Everett (2013) for a review of the linguistics literature.
} 
data and details the empirical strategy. Section 3 presents the empirical results - decomposing the impact of language from other cultural influences, using gender in language as a cultural marker to study labor supply within the household and presenting a wide range of robustness checks. Section 4 concludes.

\section{Methodology}

\section{$2.1 \quad$ Data}

\subsubsection{Economic and demographic data}

We combine data from several sources in our analysis. First, we obtain detailed demographic and economic data for the immigrant population to the U.S. from the American Community Surveys (ACS) 1\% samples from 2005 to 2015 (Ruggles et al. 2015).

We restrict the analysis to female respondents aged 25 to 49, born abroad from non-American parents, living in married-couple family households in which the husband is present, and who report speaking a language other than English in the home. Moreover, we only keep respondents that report uniquely identifiable countries of birth and languages, and for which we have information on the grammatical structure of the language reported. Appendix A.1.1 provides an exhaustive list of these sample restrictions, and details the precise process taken to construct the regression sample. It also provides precise definitions for all variables employed 6

The main dependent variable used throughout the analysis is a measure of labor market engagement, labor force participation, which is defined as an indicator equal to one if the respondent is either employed or actively looking for a job 7 As robustness check, we also analyze other labor market outcomes such as yearly weeks worked and usual weekly hours worked, both including and excluding zeros, to capture both the extensive and intensive margins of the labor supply 8

Table 1 presents summary statistics for the demographic and economic characteristics of the respondents in the regression sample. On average, the typical married women in our sample is in her upper 30s, immigrated around 15 years before, and has over 12 years of education. $60 \%$ of these respondents participate in the labor force, with $55 \%$ reporting formal employment. As can be seen from the last column of Table 1 , there is a large difference in means between the labor market outcomes for sex-based speakers and non sex-based speakers, with the former group exhibiting far lower levels of economic engagement. There is also sizeable variation in English proficiency, as well as in racial and ethnic composition for this sample. Mean

\footnotetext{
${ }^{6}$ Formal checks suggest that the regression sample is not biased by the availability of the country of birth and the linguistic data. Appendix Table C.2 provides summary statistics comparable to those in Table 1 without dropping the respondents for which the country of birth or language are not precisely identifiable, which is about $6.78 \%$ of the uncorrected regression sample. The last column of this table demonstrates that data constraints-i.e., needing to know language spoken and country of birth - do not meaningfully bias the sample in any way along these observables.

${ }^{7}$ This is the LABFORCE variable in the ACS (Ruggles et al. 2015). See appendix A.2.1 for more details.

${ }^{8}$ The yearly weeks worked correspond to the WKSWORK2 variable in the ACS (Ruggles et al. 2015). Because this variable is given in intervals, we define yearly weeks worked as the midpoint of those intervals. The usual weekly hours worked correspond to the UHRSWORK variable in the ACS (Ruggles et al. 2015). Appendix A.2.1 provides additional details.
} 
Table 1. Summary Statistics

Female Immigrants, Married, Spouse Present, Aged 25-49

\begin{tabular}{|c|c|c|c|c|c|c|}
\hline & Mean & S.d. & Min. & Max. & Obs. & SB1-SB0 \\
\hline & \multicolumn{6}{|c|}{ A. Individual characteristics } \\
\hline Age & 37.7 & 6.6 & 25 & 49 & 480,618 & $-1.0^{* * *}$ \\
\hline Years since immigration & 14.8 & 9.3 & 0 & 50 & 480,618 & -0.0 \\
\hline Age at immigration & 22.8 & 8.9 & 0 & 49 & 480,618 & $-1.0^{* * *}$ \\
\hline \multicolumn{7}{|l|}{ Educational Attainment } \\
\hline Current student & 0.06 & 0.24 & 0 & 1 & 480,618 & $-0.02 * * *$ \\
\hline Years of schooling & 12.4 & 3.7 & 0 & 17 & 480,618 & $-1.3^{* * *}$ \\
\hline No schooling & 0.05 & 0.21 & 0 & 1 & 480,618 & $0.00^{*}$ \\
\hline Elementary & 0.12 & 0.32 & 0 & 1 & 480,618 & $0.10^{* * *}$ \\
\hline High school & 0.37 & 0.48 & 0 & 1 & 480,618 & $0.10^{* * *}$ \\
\hline College & 0.46 & 0.50 & 0 & 1 & 480,618 & $-0.19 * * *$ \\
\hline \multicolumn{7}{|l|}{ Race and ethnicity } \\
\hline Asian & 0.29 & 0.46 & 0 & 1 & 480,618 & $-0.65^{* * *}$ \\
\hline Black & 0.02 & 0.14 & 0 & 1 & 480,618 & $0.01^{* * *}$ \\
\hline White & 0.47 & 0.50 & 0 & 1 & 480,618 & $0.41^{* * *}$ \\
\hline Other & 0.21 & 0.41 & 0 & 1 & 480,618 & $0.24^{* * *}$ \\
\hline Hispanic & 0.53 & 0.50 & 0 & 1 & 480,618 & $0.63^{* * *}$ \\
\hline \multicolumn{7}{|l|}{ Ability to speak English } \\
\hline Not at all & 0.11 & 0.32 & 0 & 1 & 480,618 & $0.08 * * *$ \\
\hline Not well & 0.24 & 0.43 & 0 & 1 & 480,618 & $0.02^{* * *}$ \\
\hline Well & 0.25 & 0.43 & 0 & 1 & 480,618 & $-0.08 * * *$ \\
\hline Very well & 0.40 & 0.49 & 0 & 1 & 480,618 & $-0.02^{* * *}$ \\
\hline \multicolumn{7}{|l|}{ Labor market outcomes } \\
\hline Labor participant & 0.60 & 0.49 & 0 & 1 & 480,618 & $-0.10 * * *$ \\
\hline Employed & 0.55 & 0.50 & 0 & 1 & 480,618 & $-0.12^{* * *}$ \\
\hline Yearly weeks worked (excl. 0) & 44.16 & 13.2 & 7 & 51 & 302,653 & $-1.6^{* * *}$ \\
\hline Yearly weeks worked (incl. 0) & 27.18 & 23.9 & 0 & 51 & 480,618 & $-5.8^{* * *}$ \\
\hline Weekly hours worked (excl. 0) & 36.57 & 11.4 & 1 & 99 & 302,653 & $-1.8^{* * *}$ \\
\hline Weekly hours worked (incl. 0) & 22.51 & 19.9 & 0 & 99 & 480,618 & $-5.1 * * *$ \\
\hline \multirow[t]{2}{*}{ Labor income (thds.) } & 25.3 & 28.5 & 0.0 & 536.5 & 282,057 & $-8.8^{* * *}$ \\
\hline & \multicolumn{6}{|c|}{ B. Household characteristics } \\
\hline Years since married & 12.4 & 7.5 & 0 & 39 & 352,059 & $0.14^{* * *}$ \\
\hline Number of children aged $<5$ & 0.42 & 0.65 & 0 & 6 & 480,618 & $0.04^{* * *}$ \\
\hline Number of children & 1.87 & 1.26 & 0 & 9 & 480,618 & $0.38 * * *$ \\
\hline Household size & 4.26 & 1.62 & 2 & 20 & 480,618 & $0.39 * * *$ \\
\hline Household income (thds.) & 61.0 & 59.6 & -31.0 & $1,530.3$ & 480,618 & $-20.8^{* * *}$ \\
\hline
\end{tabular}

Table 1 notes: The summary statistics are computed using sample weights (PERWT) provided in the ACS (Ruggles et al. 2015), except those for household characteristics, which are computed using household weights (HHWT). The last column reports the estimate $\widehat{\beta}$ from regressions of the type $X_{i}=\alpha+\beta$ SBI $+\varepsilon$, where $X_{i}$ is an individual level characteristic. Robust standard errors are not reported. See appendix $\mathrm{A}$ for details on variable sources and definitions.

*** Significant at the 1 percent level. ${ }^{* *}$ Significant at the 5 percent level. ${ }^{*}$ Significant at the 10 percent level

household income is just over $\$ 60,000$, and the average duration of the current marriage is 12 years. Many households have children, with the mean being almost two. Overall, the population studied contains rich variation, with over 480,000 adult female immigrants originating from 135 countries and speaking 63 different languages. Appendix Table C.1 provides the distribution of languages spoken in the regression sample and 
highlights the extensive variation in languages spoken by immigrants to the U.S. Moreover, while they are not the primary groups of interest in this analysis, we further provide similar summary statistics for the respondents' husbands in Appendix Table C.3. as well as various within-household gender gap measures in Appendix Table C.4 both of which are used in subsequent analysis.

\subsubsection{Linguistic data}

Next, we follow Gay et al. (2013) and Hicks et al. (2015), and assign to each language measures that quantify the presence and frequency of gender distinctions in its grammatical rules. We construct these measures using information compiled by linguists in the World Atlas of Language Structures (WALS, Dryer \& Haspelmath 2011). We expand the original WALS dataset in collaboration with linguists for several additional languages, making the sample more representative?

Our primary measure of gender in language is an indicator for whether a language employs a grammatical gender system based on biological sex $(\mathrm{SB})$. We also investigate gender distinctions in other features of the grammatical structure. For instance, languages with only a male and a female gender force speakers to make more sex-based distinctions than those which include a neuter gender. $\mathrm{NG}$ is an indicator variable equal to one for languages with exactly two genders, and equal to zero otherwise. Similarly, there is heterogeneity across languages in the presence and quantity of gendered personal pronouns. This feature is given by the variable GP, which captures rules related to gender agreement with pronouns. Finally, some languages assign gender due to semantic reasons only, while others assign gender due to both semantic and formal reasons, making gender more recurrent in the latter case. This feature is given by the variable GA, which captures the rules for gender assignment 10

Finally, we employ a measure of grammatical gender intensity similar to the one built by Gay et al. (2013). This measure captures how many of the above features are present in a language. It is defined as:

$$
\text { Intensity }=\mathrm{SB} \times(\mathrm{GP}+\mathrm{GA}+\mathrm{NG})
$$

where Intensity is a categorical variable that ranges from 0 to 311 The Intensity measure allows us to capture the ranking of intensity of female / male distinctions in the grammatical rules as follows. If a language has a sex-based gender system, its intensity score is the sum of its scores on the three other gender features. Hence, a strictly positive score captures languages that have strong female / male distinctions. Table 2 provides summary statistics for the language variables contained in the regression sample.

There is substantial linguistic heterogeneity in terms of grammatical gender in the sample. We demonstrate the robustness of our main findings across all of these measures, with additional checks presented in

\footnotetext{
${ }^{9}$ The languages for which some variables were compiled are detailed in appendix B For robustness, we have also verified that the exclusion of our newly assigned languages in favor of the original WALS set of languages does not alter the main findings of the analysis.

${ }^{10}$ More detailed definitions of these individual measures can be found in Hicks et al. (2015).

${ }^{11}$ This measure should not be taken as measuring absolute intensity but rather as a ranking of relative intensity across languages grammar. The discussion of the measure is extended in Appendix discussion of Table C.7
} 
Table 2. Summary Statistics, Language Variables

Female Immigrants, Married, Spouse Present, Aged 25-49

\begin{tabular}{llcccrr}
\hline \hline & Definition & Mean & S.d. & Min. & Max. & Obs. \\
\hline SB & Sex-based & 0.83 & 0.37 & 0 & 1 & 480,618 \\
NG & Number of genders & 0.72 & 0.45 & 0 & 1 & 480,618 \\
GA & Gender assignment & 0.76 & 0.43 & 0 & 1 & 480,618 \\
GP & Gender pronouns & 0.57 & 0.50 & 0 & 1 & 478,883 \\
& & & & & & 4 \\
Intensity & $($ GP + GA + NG $) \times$ SB & 2.04 & 1.21 & 0 & 3 & 478,883 \\
\hline
\end{tabular}

Table 2 notes: The summary statistics are computed using sample weights (PERWT) provided in the ACS (Ruggles et al. 2015).

Appendix Table C.7

\subsection{Empirical Strategy}

Our empirical strategy follows the epidemiological approach to culture (Fernández \& Fogli 2009, Fernández 2011, Blau et al. 2011, Blau \& Kahn 2015). This approach compares outcomes across immigrants with varying geographical origins, but living in a common institutional, legal, and social environment, thereby allowing to separate cultural influences acquired prior to migration from confounding institutional forces. In the baseline specifications, we include a set of controls that are common in analyzing decision making in the collective household framework. Moreover, to help isolate the role of language from other cultural forces, we include fixed effects by country of birth of the respondents. These fixed effects allow us to obtain identification off heterogeneity in the structure of languages spoken across immigrants from the same country of birth. We generate our core results by estimating the following specification:

$$
Y_{i j l c s t}=\alpha+\beta \mathrm{SB}_{i l}+\boldsymbol{\gamma}^{\prime} \mathbf{X}_{i j}+\boldsymbol{\delta}^{\prime} \mathbf{W}_{c}+\boldsymbol{\eta}^{\prime} \mathbf{S}_{s}+\boldsymbol{\theta}^{\prime} \mathbf{Z}_{t}+\varepsilon_{i j l c s t}
$$

where $Y_{i j l c s t}$ is a measure of labor market participation. Subscript $i$ indexes respondents; $l$, languages spoken; $j$, households; $c$, countries of birth; $s$, states of residence; $t$, ACS survey years. $\mathbf{X}_{i j}$ corresponds to the characteristics of respondent $i$ in household $j$. This vector contains the following variables: age, age squared, five-years age group indicators, race indicators, a Hispanic indicator, age at immigration to the U.S., years since in the U.S., a student indicator, years of schooling, level of English proficiency, decade of immigration indicators, number of children aged less than 5 years old in the household, and household size. $\mathbf{W}_{c}$ corresponds to a vector of indicators for the respondent's country of birth $c, \mathbf{S}_{s}$ corresponds to a vector of indicators for the respondent's state of residence $s$, and $\mathbf{Z}_{t}$ corresponds to a vector of indicators for the ACS survey year $t$. Appendices A.2.2 and A.2.3 provide details on how these variables are constructed.

To help the interpretation of regression coefficients, we additionally report in all regression tables the average of the outcome variable for the relevant sample. Moreover, to facilitate the comparison of magnitudes across coefficients from a given regression, we also report the coefficients when standardizing continuous variables between zero and one - we keep indicator variables unstandardized for ease of interpretation. 


\section{Empirical results}

\subsection{Decomposing language from other cultural influences}

Table 3 contains our baseline empirical analysis. In the first column, we examine the naïve association between gender in language and labor force participation. These results are naïve in the sense that we are not yet accounting for any confounding factors, and simply represent the difference in means across groups. The raw correlation implies that married immigrant women who speak a language that has a sex-based gender structure are 10 percentage points less likely to participate in the formal labor market. This is about $17 \%$ of the average labor force participation rate for the full regression sample.

Moving across columns in the table, the analysis includes an increasingly stringent set of controls for both observable and unobservable factors which may impact a woman's decision to participate in the labor market. The specification reported in column (2) controls for the individual characteristics of the vector $\mathbf{X}_{i j}$ described in Section 2.2. After this inclusion, the impact of the SB variable remains statistically significant and negative, while its magnitude decreases. This suggests that part of the correlation between language and labor force participation emanates from the influence of individual characteristics correlated with both language structure and behavior. The decline in the magnitude of the coefficient is largely driven by the inclusion of controls for race, not by the addition of the other respondent or household characteristics 12 Note that while we only report the coefficient of interest, the estimates on the other variables have the expected sign and magnitude. For instance, more educated respondents are more likely to be in the labor force, and those with more children aged less than five years old are less likely to be in the labor force. The coefficients for these variables are shown in Appendix Table C.6.

Table 3 also reports a measure of residual variance in the SB variable in the last row. This measure gives a sense of the variation left in the independent variable that is used in the identification of the coefficients after its correlation with other regressors has been accounted for. For instance, while the initial variance in the SB variable is 0.150 - see column (1) — , adding the rich set of household and respondent characteristics in column (2) removes roughly one third of its variation.

As the historical development of languages was intertwined with cultural and biological forces, the observed associations in column (2) could reflect the impact of language, the influence of environmental gender norms acquired prior to migration through other channels, or both. As a first step in disentangling these potential channels, column (3) controls for the average female labor participation rate in the respondents' country of birth. This variable has been the most widely used proxy to capture labor-related gender norms in an immigrant's country of birth by the epidemiological approach to culture (Fernández \& Fogli 2009, Fernández 2011, Blau \& Kahn 2015) 13 To ensure the consistency of this measure across

\footnotetext{
${ }^{12}$ Indeed, as can be seen in the last column of Table 1 Asian immigrants are more likely to speak a non sex-based language. Since they have on average higher levels of labor force participation than other respondents, this explains part of the decline in magnitude.

${ }^{13}$ To capture cultural variation in gender roles, existing studies have proxied culture with female outcomes in the country of
} 
Table 3. Gender in Language and Economic Participation, Individual Level Female Immigrants, Married, Spouse Present, 25-49 (2005-2015)

\begin{tabular}{|c|c|c|c|c|c|c|c|}
\hline \multirow[t]{2}{*}{ Dependent variable: } & \multicolumn{7}{|c|}{ Labor force participation } \\
\hline & $(1)$ & $(2)$ & $(3)$ & $(4)$ & $(5)$ & $(6)$ & $(7)$ \\
\hline $\begin{array}{l}\text { Sex-based } \\
\beta \text {-coef. }\end{array}$ & $\begin{array}{c}-0.101 * * * \\
{[0.002]}\end{array}$ & $\begin{array}{c}-0.069 * * * \\
{[0.003]}\end{array}$ & & $\begin{array}{c}-0.045^{* * *} \\
{[0.004]} \\
-0.045\end{array}$ & $\begin{array}{c}-0.027^{* * *} \\
{[0.007]}\end{array}$ & $\begin{array}{c}-0.024^{* * *} \\
{[0.007]}\end{array}$ & $\begin{array}{c}-0.021^{* * *} \\
{[0.008]}\end{array}$ \\
\hline $\begin{array}{l}\text { COB LFP } \\
\beta \text {-coef. }\end{array}$ & & & $\begin{array}{c}0.002^{* * *} \\
{[0.000]} \\
0.041\end{array}$ & $\begin{array}{c}0.002^{* * *} \\
{[0.000]} \\
0.039\end{array}$ & & & \\
\hline $\begin{array}{l}\text { Past migrants LFP } \\
\beta \text {-coef. }\end{array}$ & & & $\begin{array}{c}0.005^{* * *} \\
{[0.000]} \\
0.063\end{array}$ & $\begin{array}{c}0.005^{* * *} \\
{[0.000]} \\
0.062\end{array}$ & & & \\
\hline $\begin{array}{l}\text { Respondent char. } \\
\text { Age } \\
\text { Race and ethnicity } \\
\text { Education } \\
\text { Years since immig. } \\
\text { Age at immig. } \\
\text { Decade of immig. } \\
\text { English prof. }\end{array}$ & $\begin{array}{l}\text { No } \\
\text { No } \\
\text { No } \\
\text { No } \\
\text { No } \\
\text { No } \\
\text { No }\end{array}$ & $\begin{array}{l}\text { Yes } \\
\text { Yes } \\
\text { Yes } \\
\text { Yes } \\
\text { Yes } \\
\text { Yes } \\
\text { Yes }\end{array}$ & $\begin{array}{l}\text { Yes } \\
\text { Yes } \\
\text { Yes } \\
\text { Yes } \\
\text { Yes } \\
\text { Yes } \\
\text { Yes }\end{array}$ & $\begin{array}{l}\text { Yes } \\
\text { Yes } \\
\text { Yes } \\
\text { Yes } \\
\text { Yes } \\
\text { Yes } \\
\text { Yes }\end{array}$ & $\begin{array}{l}\text { Yes } \\
\text { Yes } \\
\text { Yes } \\
\text { Yes } \\
\text { Yes } \\
\text { Yes } \\
\text { Yes }\end{array}$ & $\begin{array}{l}\text { Yes } \\
\text { Yes } \\
\text { Yes } \\
\text { Yes } \\
\text { Yes } \\
\text { Yes } \\
\text { Yes }\end{array}$ & $\begin{array}{l}\text { Yes } \\
\text { Yes } \\
\text { Yes } \\
\text { Yes } \\
\text { Yes } \\
\text { Yes } \\
\text { Yes }\end{array}$ \\
\hline $\begin{array}{l}\text { Household char. } \\
\text { Children aged }<5 \\
\text { Household size } \\
\text { State }\end{array}$ & $\begin{array}{l}\text { No } \\
\text { No } \\
\text { No }\end{array}$ & $\begin{array}{l}\text { Yes } \\
\text { Yes } \\
\text { Yes }\end{array}$ & $\begin{array}{l}\text { Yes } \\
\text { Yes } \\
\text { Yes }\end{array}$ & $\begin{array}{l}\text { Yes } \\
\text { Yes } \\
\text { Yes }\end{array}$ & $\begin{array}{l}\text { Yes } \\
\text { Yes } \\
\text { Yes }\end{array}$ & $\begin{array}{l}\text { Yes } \\
\text { Yes } \\
\text { Yes }\end{array}$ & $\begin{array}{l}\text { Yes } \\
\text { Yes } \\
\text { Yes }\end{array}$ \\
\hline $\begin{array}{l}\text { COB char. } \\
\text { Geography } \\
\text { Fertility } \\
\text { Migration rate } \\
\text { Education } \\
\text { GDP per capita } \\
\text { Common language } \\
\text { Genetic distance }\end{array}$ & $\begin{array}{l}\text { No } \\
\text { No } \\
\text { No } \\
\text { No } \\
\text { No } \\
\text { No } \\
\text { No }\end{array}$ & $\begin{array}{l}\text { No } \\
\text { No } \\
\text { No } \\
\text { No } \\
\text { No } \\
\text { No } \\
\text { No }\end{array}$ & $\begin{array}{l}\text { Yes } \\
\text { Yes } \\
\text { Yes } \\
\text { Yes } \\
\text { Yes } \\
\text { Yes } \\
\text { Yes }\end{array}$ & $\begin{array}{l}\text { Yes } \\
\text { Yes } \\
\text { Yes } \\
\text { Yes } \\
\text { Yes } \\
\text { Yes } \\
\text { Yes }\end{array}$ & $\begin{array}{l}\text { No } \\
\text { No } \\
\text { No } \\
\text { No } \\
\text { No } \\
\text { No } \\
\text { No }\end{array}$ & $\begin{array}{l}\text { No } \\
\text { No } \\
\text { No } \\
\text { No } \\
\text { No } \\
\text { No } \\
\text { No }\end{array}$ & $\begin{array}{l}\text { No } \\
\text { No } \\
\text { No } \\
\text { No } \\
\text { No } \\
\text { No } \\
\text { No }\end{array}$ \\
\hline $\mathrm{COB} F \mathrm{FE}$ & No & No & No & No & Yes & Yes & Yes \\
\hline $\mathrm{COB} \times$ decade mig. $\mathrm{FE}$ & No & No & No & No & No & Yes & Yes \\
\hline County FE & No & No & No & No & No & No & Yes \\
\hline $\begin{array}{l}\text { Observations } \\
\mathrm{R}^{2}\end{array}$ & $\begin{array}{c}480,618 \\
0.006\end{array}$ & $\begin{array}{c}480,618 \\
0.110\end{array}$ & $\begin{array}{c}451,048 \\
0.129\end{array}$ & $\begin{array}{c}451,048 \\
0.129\end{array}$ & $\begin{array}{c}480,618 \\
0.132\end{array}$ & $\begin{array}{c}480,618 \\
0.138\end{array}$ & $\begin{array}{c}382,556 \\
0.145\end{array}$ \\
\hline $\begin{array}{l}\text { Mean } \\
\text { SB residual variance }\end{array}$ & $\begin{array}{c}0.60 \\
0.150\end{array}$ & $\begin{array}{c}0.60 \\
0.098\end{array}$ & 0.60 & $\begin{array}{c}0.60 \\
0.049\end{array}$ & $\begin{array}{c}0.60 \\
0.013\end{array}$ & $\begin{array}{c}0.60 \\
0.012\end{array}$ & $\begin{array}{c}0.60 \\
0.012\end{array}$ \\
\hline
\end{tabular}

origin. For instance, Fernández \& Fogli (2009) use for country of origin female labor force participation to capture the culture of second generation immigrants to the U.S. Blau \& Kahn (2015) additionally control for individual labor force participation prior to migration to separate culture from social capital. Oreffice (2014) create an index of gender roles in the country of origin as a function of several gender outcomes. This literature posits that immigrants carry with them some of the attitudes from their home country to the U.S., and, in the case of second generation immigrants, that immigrants transmit some of these attitudes to their children. 
time and countries, we use the ratio of female to male labor participation rates rather than the raw female labor participation rates. Moreover, we assign the value of this variable at the time of immigration of the respondent to better capture the conditions in which she formed her preferences regarding gender roles. We also control for the average labor participation rate of married female immigrants to the U.S. from the respondent's country of birth a decade before the time of her migration. We construct this variable using the U.S. censuses from 1940 to 2000 and the ACS from 2010 to 2014 (Ruggles et al. 2015). This approach allows us to address potential forms of selection regarding the culture of the country of origin of respondents that may be different from the culture of the average citizen, since immigrants are a selected pool. It also allows us to capture some degree of oblique cultural transmission by looking at whether the behavior of same country immigrants that arrived to the U.S. a decade earlier than the respondent could play an independent role. To account for the influence of historical contact across populations and the development of gender norms among groups, we also control for a measure of genetic distance from the U.S. (Spolaore \& Wacziarg $2009,2016) 14$ We further control for various country-level characteristics such as GDP per capita, total fertility rate, an indicator for whether the country of birth shares a common language with those spoken by at least $9 \%$ of the population in the U.S.-English and Spanish-, years of schooling in the country of birth, and various geographic measures - latitude, longitude, and bilateral distance to the U.S ${ }^{15}$ It is important to include these factors since they can control for some omitted variables that correlate with country of origin gender norms.

We find that a one standard deviation increase in female labor force participation rates in one's country of birth (18\%) is associated with a 4 percentage points increase in one's labor force participation. Our results imply a larger magnitude for the correlation with the labor force participation of married female immigrants that migrated a decade prior to the respondent, wherein a one standard deviation increase in their average labor participation rate $(12 \%)$ is associated with a 5 percentage points increase in labor force participation. These results largely confirm previous findings in the literature using the epidemiological approach to culture (Fernández \& Fogli 2009, Blau \& Kahn 2015).

In column (4), we add the SB measure to compare the magnitude of its impact on individual behavior to that of the usual country-level proxies used in the literature. Including these variables altogether imposes a very stringent test on the data. To see this, refer again to the bottom of Table 3 which reports the residual variation in SB used for identification. This metric is cut in half as we move from column (2) to column (4), implying a correlation between language structure and the usual country-level proxies of gender roles

\footnotetext{
${ }_{14}$ Alternatively, we checked the robustness of our results to measures of linguistic distance between languages from Adsera \& Pytlikova (2015), including a Linguistic proximity index constructed using data from Ethnologue and a Levenshtein distance measure developed by the Max Planck Institute for Evolutionary Anthropology This data covers 42 languages out of the 63 in our regression sample. Even with a reduced sample size (435,899 observations instead of 480,619 observations), the results from the baseline regressionthe regression from Table 3 column (5) with country of birth fixed effectsare essentially unchanged. Because of such a lower coverage of languages the use of linguistic distance as a control would entail, we do not include these measures throughout the analysis.

${ }^{15}$ See Appendix A.2.6 for more details about the sources and the construction of the country-level variables. See also appendix Table C.5 which reports summary statistics for these variables.
} 
used in the literature 16 In spite of this, while the coefficient on sex-based language diminishes somewhat in magnitude, it remains highly statistically significant, sizeable, and negative even after adding these controls. This suggests that language structure may capture unobservable cultural characteristics at the country-level beyond the proxies used in the literature. This is promising as it shows that language likely captures some cultural features not previously uncovered.

Nevertheless, while column (4) controls for an exhaustive list of country of birth characteristics as well as language structure, there may still be some unobservable cultural components that vary systematically across countries and that can be captured neither by language nor by country of birth controls. Since immigrants from the same country may speak languages with varying structures, our analysis can uniquely address this issue by further including a set of country of birth fixed effects and exploiting within country variation in the structure of language spoken in the pool of immigrants in the U.S. Because these fixed effects absorb the impact of all time invariant factors at the country level, this means that identification of any language effect relies on heterogeneity in the structure of language spoken within a pool of immigrants from the same country of origin. The addition of 134 country of birth fixed effects noticeably reduce the potential sources of identification, as the residual variance in SB is only one tenth of its original value. Yet again, the impact of language remains highly significant and economically meaningful. Gender assigned females are 2.7 percentage points less likely to participate in the labor force than their non-gender assigned counterparts. This suggests that while the cultural components common to all immigrants from the same origin country carried in the structure of language drive a large part the results compared to the estimates in column (2), about one third of the effect can still be attributed to either more local components of culture or to alternative channels such as a cognitive mechanism through which language would impact behavioral outcomes directly.

Note that because identification now comes from within country variation in the structure of languages spoken, the estimates, while gaining in credibility, could be decreasing in representativeness. For instance, they no longer provide information about the impact of language structure on the working behavior of female immigrants that are from linguistically homogeneous countries. To better understand the extent to which each country of birth contributes to the identification, we adapt Aronow \& Samii's (2016) procedure to uncover the "effective sample" used in the regression. This procedure generates regression weights by computing the relative size of the residual variance in the SB variable for each country of birth in the sample. Not surprisingly, we find that immigrants born in linguistically heterogeneous countries are the prime contributors in building the estimate. In fact, empirical identification in the full fixed effect regressions comes from counties such as India, the Philippines, Vietnam, China, Afghanistan, and Canada. Appendix Figure D.1 makes this point clearer by mapping these regression weights.

Despite the fact that culture is a slow-moving institution, it can evolve, and language may itself constrain or facilitate cultural evolution in certain directions. We check that this does not impact our results by adding country of birth fixed effects interacted with decade of migration in column (6). This allows us to capture, to

\footnotetext{
${ }^{16}$ This is not surprising given the cross-country results in Gay et al. (2013), which show that country-level female labor participation rates are correlated with the linguistic structure of the majority language.
} 
some extent, country-level cultural aspects that could be time variant. The results are largely unchanged by this addition, suggesting that language structure captures permanent aspects that operate at the individual level.

Finally, note that all the regressions reported in Table 3 include state of residence fixed effects to account for the possibility that location choices are endogenous to the language spoken by the community of immigrants that the respondent belongs to. However, this phenomenon could operate at a lower geographic level than that of the state. Therefore, we include county of residence fixed effects in column (7), so that we can effectively compare female immigrants that reside in the same county but speak a language with a varying structure. Unfortunately, the ACS do not systematically provide respondents' county of residence, so that we are only able to include $80 \%$ of the respondents in the original regression sample - see Appendix A.2.3 for more details. As a results, the regression coefficient in column (7) is not fully comparable with the results in other specifications. Nevertheless, the magnitude and significance of the estimate on the SB variable remains largely similar to the one in column (6), suggesting that if there is selection into location, it does not drive our main results.

Overall, our findings strongly suggest that while sex-based distinctions in language are deeply rooted in historical cultural forces, gender in language appears to retain a disti

nct association with gender in behavior which is independent of these other factors.

\subsection{Language and the household}

Given the failure of the unitary model of household decision-making, standard theory has developed frameworks where bargaining is key to explaining household behavior (Chiappori et al. 2002, Blundell et al. 2007). In this section we analyze whether the impact of language is mediated by household characteristics in the following ways. First, household bargaining power may mediate or influence the impact of language. For example, females with high bargaining power may not be bound by the gender roles that languages can embody. To shed light on the mechanism behind the association between language and female labor supply, we analyze in section 3.2 .1 the impact of the distribution of bargaining power within the household. Second, we investigate in section 3.2 .2 the impact of the language spoken by the husband. While the majority of immigrant households in the data are linguistically homogeneous, roughly $20 \%$ are not. This variation allows us to analyze the relative role of the language structures of both spouses, potentially shedding additional light on whether language use within the household matters. Since marriage is more likely among individuals who share the same language, we need to rule out the possibility that our results overestimate the impact of language via selection effects. This could be the case if marriages into linguistically homogeneous languages reflected attachment to one's own culture. To deal with such selection issues, we compare the behavior of these two types of households and exploit information on whether marriage predates migration. 


\subsubsection{Language and household bargaining power}

In this section, we examine the impact of language taking into account bargaining power characteristics within the household. Throughout, we restrict the sample to households where both spouses speak the same language. We consider these households to avoid conflating other potential language effects. This exercise complements recent theoretical advances by analyzing whether the impact of bargaining power in the household is culturally dependent. In particular, the collective model of labor supply predicts that women with lower bargaining power work more, while those with higher bargaining power work less since they are able to substitute leisure for work. At the same time, these model typically do not consider social norms. This may be problematic, as Field et al. (2016) show that including social norms into a collective labor supply model can lead to the opposite prediction, namely that women with lower bargaining power work less 17

For the sake of comparison, we report in column (1) of Table 4 the results when replicating column (5) of Table 3 with this alternative sample of linguistically homogeneous households. Women speaking a sex-based language are 3.1 percentage points less likely to participate in the labor force than their non-gender assigned counterparts. This is slightly larger in magnitude than in the unrestricted sample, where the effect is of 2.7 percentage points.

To capture bargaining power within the household, we follow Oreffice (2014) and control for the age gap as well as the non-labor income gap between spouses 18 In column (2), we exclude the language variable to derive a baseline when using these new controls. These regressions include controls for husbands characteristics similar to those of the respondents used in Table $33^{19}$ Consistent with previous work, we find that the larger the age gap and the larger the non-labor income gap, the less likely women are to participate in the labor force: a one standard deviation increase in the age gap is associated with a reduction in the wifes labor force participation of 1.8 percentage point. Similarly, a one standard deviation increase in the non-labor income gap is associated with a reduction in the wifes labor force participation of 2.1 percentage points. These results corroborate Oreffice (2014) and Field et al. (2016) which show that the impact of bargaining power is different in households with traditional gender roles relative to the U.S., and that female immigrants with low bargaining power are less likely to participate in the labor market 20

In column (3), we add the SB variable. The coefficient is largely unchanged compared to column (1) as women speaking a sex-based language are 2.7 percentage points less likely to participate in the labor force

\footnotetext{
${ }^{17}$ Field et al. (2016) implement a field experiment in India where traditional gender norms bound women away from the labor market, and investigate how a change in their bargaining power stemming from an increase in their control over their earnings can allow them to free themselves from the traditional gender norms.

${ }^{18}$ We focus on the non-labor income gap because it is relatively less endogenous than the labor income gap (Lundberg et al. 1997). We do not include the education gap for the same reason. Appendix Table C.4 presents descriptive statistics for various gender gap measures within the household. Other variables, such as physical attributes, have been shown to influence female labor supply (Oreffice \& Quintana-Domeque 2012). Unfortunately, they are not available in the ACS (Ruggles et al. 2015).

${ }^{19}$ Appendix Table C.3 presents descriptive statistics for these husband characteristics.

${ }^{20}$ This also consistent with findings in Hicks et al. (2015), wherein the division of household labor was shown to be heavily skewed against females in households coming from countries with a dominantly sex-based language, suggesting that languages could potentially constrain females to a traditional role within the household.
} 
Table 4. Language Structure and Household Bargaining

Same Language Married Couples (2005-2015)

\begin{tabular}{|c|c|c|c|c|c|c|}
\hline \multirow[t]{2}{*}{ Dependent variable: } & \multicolumn{6}{|c|}{ Labor force participation } \\
\hline & (1) & $(2)$ & (3) & (4) & $(5)$ & (6) \\
\hline Sex-based & $\begin{array}{c}-0.031^{* * *} \\
{[0.008]}\end{array}$ & & $\begin{array}{c}-0.027^{* * *} \\
{[0.008]}\end{array}$ & $\begin{array}{c}-0.022^{* *} \\
{[0.009]}\end{array}$ & $\begin{array}{c}-0.021^{*} \\
{[0.013]}\end{array}$ & $\begin{array}{c}-0.023^{* * *} \\
{[0.009]}\end{array}$ \\
\hline$\beta$-coef. & -0.031 & & -0.027 & -0.022 & -0.021 & -0.022 \\
\hline Age gap & & $\begin{array}{c}-0.003^{* * *} \\
{[0.001]}\end{array}$ & $\begin{array}{c}-0.003^{* * *} \\
{[0.001]}\end{array}$ & $\begin{array}{c}-0.006^{* * *} \\
{[0.001]}\end{array}$ & $\begin{array}{c}0.003 \\
{[0.002]}\end{array}$ & $\begin{array}{c}-0.007^{* * *} \\
{[0.001]}\end{array}$ \\
\hline$\beta$-coef. & & -0.018 & -0.018 & -0.034 & 0.013 & -0.035 \\
\hline Non-labor income gap & & $\begin{array}{c}-0.001^{* * *} \\
{[0.000]}\end{array}$ & $\begin{array}{c}-0.001^{* * *} \\
{[0.000]}\end{array}$ & $\begin{array}{c}-0.001^{* * *} \\
{[0.000]}\end{array}$ & $\begin{array}{c}-0.001^{* * *} \\
{[0.000]}\end{array}$ & $\begin{array}{c}-0.001^{* * *} \\
{[0.000]}\end{array}$ \\
\hline$\beta$-coef. & & -0.021 & -0.021 & -0.021 & -0.018 & -0.015 \\
\hline Age gap $\times \mathrm{SB}$ & & & & & & $\begin{array}{c}0.000 \\
{[0.000]}\end{array}$ \\
\hline$\beta$-coef. & & & & & & 0.002 \\
\hline Non-labor income gap $\times$ SB & & & & & & $\begin{array}{c}-0.000 * * * \\
{[0.000]}\end{array}$ \\
\hline$\beta$-coef. & & & & & & -0.008 \\
\hline Respondent char. & Yes & Yes & Yes & Yes & Yes & Yes \\
\hline Household char. & Yes & Yes & Yes & Yes & Yes & Yes \\
\hline Respondent COB FE & Yes & Yes & Yes & Yes & Yes & Yes \\
\hline Husband char. & No & Yes & Yes & Yes & Yes & Yes \\
\hline Husband COB FE & No & No & No & Yes & Yes & Yes \\
\hline Sample mar. before mig. & No & No & No & No & Yes & No \\
\hline Observations & 409,017 & 409,017 & 409,017 & 409,017 & 154,983 & 409,017 \\
\hline $\mathrm{R}^{2}$ & 0.134 & 0.145 & 0.145 & 0.147 & 0.162 & 0.147 \\
\hline Mean & 0.59 & 0.59 & 0.59 & 0.59 & 0.55 & 0.59 \\
\hline $\mathrm{SB}$ residual variance & 0.011 & & 0.011 & 0.010 & 0.012 & 0.013 \\
\hline
\end{tabular}

Table 4 notes: The estimates are computed using sample weights (PERWT) provided in the ACS (Ruggles et al. 2015). See appendix A for details on variable sources and definitions.

*** Significant at the 1 percent level. ${ }^{* *}$ Significant at the 5 percent level. ${ }^{*}$ Significant at the 10 percent level

than their non-gender assigned counterparts. This suggests that language has an impact that is not mediated by the distribution of bargaining power within the household. Furthermore, the impact of language is of comparable magnitude as that of either the non-labor income gap or the age gap, suggesting that cultural forces are equally important than bargaining measures in determining female labor forces participation.

In $16 \%$ of households where both spouses speak the same language, spouses were born in different countries. To account for any impact this may have on the estimates, we add husband country of birth fixed effects in column (4). Reassuringly, the results are largely unchanged by this addition. Similarly, some of the observed effect may result from selection into same culture marriages. To assess whether such selection effect drives the results, we run the specification of column (4) on the subsample of spouses that married before migration. Since female immigrants married to their husbands prior to migration ("tied women") may have different motivations, this subsample should provide a window into whether we should worry about 
selection among couples after migration. Note that because this information is only available in the ACS after 2008, the resulting estimate is not fully comparable to others in Table 4 Nevertheless, the magnitude of the estimate on the language variable remains largely unchanged - although the dramatic reducation in the sample size reduces our statistical power. The impact of non-labor income gap also remains roughly similar, while the age gap coefficient becomes insignificant and positive. Overall, these results suggest that our main findings are not driven by selection into linguistically homogeneous marriages.

Again motivated by Oreffice (2014) and Field et al. (2016), we investigate the extent to which gender roles, as embodied by gender in language, are reinforced in households where the wife has weak bargaining power or vice versa. In column (6) of Table 4 , we add interaction terms between the SB language variable and the non-labor income gap as well as the age gap. After this addition, the estimate on the language measure remains identical to the one in column (4), suggesting that language has a direct effect that is not completely mediated through bargaining power. The only significant interaction is between the language variable and the non-labor income gap. In particular, a one standard deviation increase in the size of the non-labor income gap leads to an additional decrease of 0.8 percentage points in the labor participation of women speaking a sex-based language compared to others that does not. While the effect is arguably small in magnitude, it does confirm Field et al. (2016) insofar as married females with low bargaining power are more likely to be bound by traditional gender roles, and less likely to participate in the labor market. Appendix Table C.12 replicates the analysis carried out in column (6) alternative measures of labor market engagement. As in previous analyses, the results are similar for the extensive margin but less clear for the intensive margin.

\subsubsection{Evidence from linguistic heterogeneity within the household}

So far, we have shown that the impact of gender in language on gender norms regarding labor market participation was robust to controlling for husband characteristics as well as husband country of origin fixed effects. In this section, we analyze the role of gender norms embodied in a husband's language on his wife's labor participation. Indeed, Fernández \& Fogli (2009) find that gender roles in the husband's country of origin characteristics play an important role in determining the working behavior of his wife.

In Table 5, we pool together all households, and compare households where both spouses speak a sexbased language to households where only one speaker does so, paying attention to whether this speaker is the husband or the wife 21 We also consider husbands that speak English. Because English speaking husbands may provide assimilation services to their wives, we include an indicator for English speaking husbands to sort out the impact of the language structure from these assimilation services.

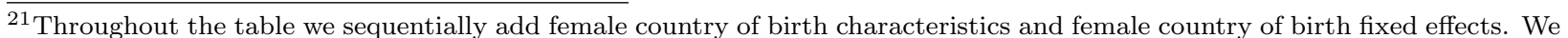
do not add the respondent's husband country of birth fixed characteristics because only $20 \%$ of the sample features husbands and wives speaking different structure languages. In that case, our analysis does not have sufficient statistical power precisely identify the coefficients. While many non-English speaking couples share the same language in the household, we focus on the role of gender marking to learn about the impact of husbands and wives gender norms as embodied in the structure of their language.
} 
Table 5. Linguistic Heterogeneity in the Household Immigrant Households (2005-2015)

\begin{tabular}{lccccc}
\hline \hline Dependent variable: & \multicolumn{5}{c}{ Labor force participation } \\
\cline { 2 - 6 } & $(1)$ & $(2)$ & $(3)$ & $(4)$ & $(5)$ \\
\cline { 2 - 6 } Same $\times$ wife's sex-based & $-0.068^{* * *}$ & $-0.069^{* * *}$ & $-0.070^{* * *}$ & $-0.040^{* * *}$ & $-0.015^{*}$ \\
& {$[0.003]$} & {$[0.003]$} & {$[0.003]$} & {$[0.005]$} & {$[0.008]$} \\
Different $\times$ wife's sex-based & $-0.043^{* * *}$ & & $-0.044^{* * *}$ & -0.015 & 0.006 \\
& {$[0.014]$} & & {$[0.014]$} & {$[0.015]$} & {$[0.016]$} \\
Different $\times$ husband's sex-based & & $-0.031^{* * *}$ & $-0.032^{* * *}$ & -0.008 & 0.001 \\
& & {$[0.011]$} & {$[0.011]$} & {$[0.012]$} & {$[0.011]$} \\
Respondent char. & & & & & \\
Household char. & Yes & Yes & Yes & Yes & Yes \\
Husband char. & Yes & Yes & Yes & Yes & Yes \\
Respondent COB char. & Yes & Yes & Yes & Yes \\
Respondent COB FE & No & No & No & Yes & No \\
Observations & No & No & No & No & Yes \\
$\mathrm{R}^{2}$ & & & & & \\
& 387,037 & 387,037 & 387,037 & 364,383 & 387,037 \\
Mean & 0.122 & 0.122 & 0.122 & 0.143 & 0.146 \\
SB residual variance & & & & \\
\hline
\end{tabular}

Table 5 notes: The estimates are computed using sample weights (perwt) provided in the ACS (Ruggles et al. 2015). See appendix A for details on variable sources and definitions.

*** Significant at the 1 percent level. ${ }^{* *}$ Significant at the 5 percent level. ${ }^{*}$ Significant at the 10 percent level

In column (1) of Table 5, the wife's language variable SB is interacted with two indicators that capture whether a wife and her spouse both speak a language that has the same grammatical structure 22 Women speaking a sex-based language in a household with a husband speaking a sex-based language as well are almost 7 percentage points less likely to be in the labor force. Conversely, women speaking a sex-based language in a household with a husband speaking a non sex-based language are only 4.3 percentage points less likely to be part of the labor force. To further explore the role of the husbands' languages, we run in column (2) the same specification as in column (1) except that we use the husband's language variable rather than the wife's. The results are very close to those in column (1) but suggest that while a husband's gender norms matter for a wife's behavior, they seem to play a slightly weaker albeit still significant role. Column (3) includes both spouses' language variables. Overall, this suggests that the impact of language structure is stronger when the languages of both spouses are sex-based. Furthermore, when speaking languages with different gender structures, the impact of the respondent's language is bigger than the impact of the husband's language, suggesting cultural spillovers within the household. Finally, columns (4) and (5) of Table 5 add country of birth characteristics and country of birth fixed effects, respectively. The impact of the husband's language remains significant in linguistically homogeneous households, but not in heterogeneous ones. Nevertheless, it seems that part of this loss in precision is due to the steep decline in statistical power, as testified by the

\footnotetext{
${ }^{22}$ Instead of simply comparing households where husbands and wives speak the same language versus those without, this approach allows us both to include households with English speakers and to understand whether the observed mechanisms operate through grammatical gender.
} 
decline in the residual variance in $\mathrm{SB} 23$

\subsection{Language and social interactions}

Immigrants tend to cluster in ethnic enclaves, partly because doing so allows them to access a network were information is exchanged (Edin et al. 2003, Munshi 2003). Within those networks, speaking a common language may facilitate such exchanges. Furthermore, language itself is a network technology which value increases with the number of speakers. Being able to communicate within a dense ethnic network may be particularly important for female immigrants, to share information, communicate about job opportunities, and reduce information asymmetries between job seekers and potential employers. This effect may encourage female labor force participation. At the same time, sharing the same linguistic and cultural background within a dense ethnic network may reinforce the social norms that the language act as a vehicle for. This is even more so if increasing language use makes gender categories more salient, or if sharing the same cultural background makes social norms bind more strongly. As a result, female immigrants living in an ethnic enclave may face a trade-off between, on the one hand, increased job opportunities through informal network channels, and, on the other hand, increased peer pressure to conform with social norms. This second effect may itself depend on the extent to which the ethnic group social norms are biased in favor of traditional gender roles that encourage women to stay out of the labor force.

This potential trade-off guides the empirical analysis presented in Table 6. In what follows, we rely on the subsample of immigrants residing in the counties that are identifiable in the ACS. This corresponds to roughly 80 percent of the initial sample ${ }^{24}$ To capture the impact of social interactions, we build two measures of local ethnic and linguistic network density. Density COB is the ratio of the immigrant population born in the respondent's country of birth and residing in the respondent's county to the total number of immigrants residing in the respondent's county. Similarly, Density language is the ratio of the immigrant population speaking the respondent's language and residing in the respondent's county to the total number of immigrants residing in the respondent's county 25

Throughout Table 66 we control for respondent characteristics and household characteristics. In the full specification we also control for respondent country of birth fixed effects. In column (1) of Table 6 . we exclude the language variable and include the density of the respondent's country of birth network. The density of the network has a negative impact on the respondent's labor participation, suggesting that peer pressure from immigrants coming from the same country of origin to comply with social norms may be stronger than improvements in access to job opportunities. In column (2), we add both the language variable and the interaction term between language and the network density measure. The magnitude of

\footnotetext{
${ }^{23}$ In all cases however, when a wife speaks a sex-based language, she exhibits on average lower female labor force participation.

${ }^{24}$ See Appendix A.2.3 for more details on the number of identifiable counties in the ACS. Although estimates on this subsample may not be comparable with those obtained with the full sample, the results column (7) of Table 3 being so similar to those in column (6) gives us confidence that selection into county does not drive the results.

${ }^{25}$ In both measures, we use the total number of immigrants that are in the workforce because it is more relevant for networking and reducing information asymmetries regarding labor market opportunities. See Appendix A.2.7 for more details.
} 
the coefficients imply that language and network densities play different roles that reinforce each other. In particular, the results suggest that peer pressure to comply with social norms may be stronger among female immigrants that speak a sex-based language, as the interaction term is negative. Also, the impact of the respondent's network is now strongly positive, suggesting that, on its own, living in a county with a dense ethnic network does increase labor force participation once cultural factors are taken into account. Finally, the coefficient on the language variable is still negative and significant, and has the same magnitude as in all other specifications. In columns (3) and (4), we repeat the same exercise using instead the network density in language spoken as criteria to define ethnic density. The results and interpretation are broadly similar to the previous ones. Finally, we add both types of network density measures together in columns (5) and (6). The results suggest that ethnic networks defined using country of birth matter more than networks defined purely along linguistic lines.

Table 6. Language and Social Interactions

Respondents In Identifiable Counties (2005-2015)

\begin{tabular}{|c|c|c|c|c|c|c|}
\hline \multirow[t]{2}{*}{ Dependent variable: } & \multicolumn{6}{|c|}{ Labor force participation } \\
\hline & (1) & $(2)$ & (3) & $(4)$ & $(5)$ & $(6)$ \\
\hline Sex-based & & $\begin{array}{c}-0.023^{* * *} \\
{[0.003]}\end{array}$ & & $\begin{array}{c}-0.037^{* * *} \\
{[0.003]}\end{array}$ & $\begin{array}{c}-0.026^{* * *} \\
{[0.003]}\end{array}$ & $\begin{array}{c}-0.016^{*} \\
{[0.008]}\end{array}$ \\
\hline$\beta$-coef. & & -0.225 & & -0.245 & -0.197 & -0.057 \\
\hline Density COB & $\begin{array}{c}-0.001 * * * \\
{[0.000]}\end{array}$ & $\begin{array}{c}0.009^{* * *} \\
{[0.000]}\end{array}$ & & & $\begin{array}{c}0.009^{* * *} \\
{[0.001]}\end{array}$ & $\begin{array}{c}0.003^{* * *} \\
{[0.001]}\end{array}$ \\
\hline$\beta$-coef. & -0.020 & 0.223 & & & 0.221 & 0.067 \\
\hline Density $\mathrm{COB} \times \mathrm{SB}$ & & $\begin{array}{c}-0.009 * * * \\
{[0.000]}\end{array}$ & & & $\begin{array}{c}-0.010^{* * *} \\
{[0.001]}\end{array}$ & $\begin{array}{c}-0.002^{* * *} \\
{[0.001]}\end{array}$ \\
\hline$\beta$-coef. & & -0.243 & & & -0.254 & -0.046 \\
\hline Density language & & & $\begin{array}{c}0.000^{* *} \\
{[0.000]}\end{array}$ & $\begin{array}{c}0.007^{* * *} \\
{[0.000]}\end{array}$ & $\begin{array}{l}-0.000 \\
{[0.001]}\end{array}$ & $\begin{array}{l}-0.000 \\
{[0.001]}\end{array}$ \\
\hline$\beta$-coef. & & & 0.006 & 0.203 & -0.001 & -0.007 \\
\hline Density language $\times \mathrm{SB}$ & & & & $\begin{array}{c}-0.007 * * * \\
{[0.000]}\end{array}$ & $\begin{array}{c}0.001 * * \\
{[0.001]}\end{array}$ & $\begin{array}{l}-0.000 \\
{[0.001]}\end{array}$ \\
\hline$\beta$-coef. & & & & -0.201 & 0.038 & -0.004 \\
\hline Respondent char. & Yes & Yes & Yes & Yes & Yes & Yes \\
\hline Household char. & Yes & Yes & Yes & Yes & Yes & Yes \\
\hline Respondent COB FE & No & No & No & No & No & Yes \\
\hline Observations & 382,556 & 382,556 & 382,556 & 382,556 & 382,556 & 382,556 \\
\hline $\mathrm{R}^{2}$ & 0.110 & 0.113 & 0.110 & 0.112 & 0.114 & 0.134 \\
\hline Mean & 0.60 & 0.60 & 0.60 & 0.60 & 0.60 & 0.60 \\
\hline SB residual variance & & 0.101 & & 0.101 & 0.101 & 0.013 \\
\hline
\end{tabular}

Table 6 notes: The estimates are computed using sample weights (PERWT) provided in the ACS (Ruggles et al. 2015). See appendix A for details on variable sources and definitions.

*** Significant at the 1 percent level. ${ }^{* *}$ Significant at the 5 percent level. ${ }^{*}$ Significant at the 10 percent level 


\subsection{Robustness checks}

Alternative language variables and labor market outcomes This section presents an extensive list of robustness checks of the main results in Table 3 , column (5) - a specification that includes country of birth fixed effects. First, Table 7 reports the results when using alternative measures of female labor participation, together with alternative language variables.

Table 7. Gender in Language and Economic Participation, Additional Outcomes Replication of Column 5 of Table 3 . All Language Variables

\begin{tabular}{|c|c|c|c|c|c|c|}
\hline \multirow{4}{*}{ Dependent variable: } & \multicolumn{2}{|c|}{ Extensive margin } & \multicolumn{4}{|c|}{ Intensive margins } \\
\hline & \multirow[b]{2}{*}{$\begin{array}{l}\text { LFP } \\
(1)\end{array}$} & \multirow[b]{2}{*}{$\begin{array}{l}\text { Employed } \\
(2)\end{array}$} & \multicolumn{2}{|c|}{ Including zeros } & \multicolumn{2}{|c|}{ Excluding zeros } \\
\hline & & & $\begin{array}{l}\text { Weeks } \\
(3)\end{array}$ & $\begin{array}{l}\text { Hours } \\
(4)\end{array}$ & $\begin{array}{l}\text { Weeks } \\
(5)\end{array}$ & $\begin{array}{l}\text { Hours } \\
(6)\end{array}$ \\
\hline & \multicolumn{6}{|c|}{ Panel A. Sex-based } \\
\hline SB & $\begin{array}{c}-0.027^{* * *} \\
{[0.007]}\end{array}$ & $\begin{array}{c}-0.028^{* * *} \\
{[0.007]}\end{array}$ & $\begin{array}{c}-1.01^{* * *} \\
{[0.34]}\end{array}$ & $\begin{array}{c}-0.813^{* * *} \\
{[0.297]}\end{array}$ & $\begin{array}{l}-0.24 \\
{[0.24]}\end{array}$ & $\begin{array}{l}-0.165 \\
{[0.229]}\end{array}$ \\
\hline \multirow[t]{2}{*}{$\mathrm{R}^{2}$} & $\begin{array}{c}480,618 \\
0.132\end{array}$ & $\begin{array}{c}480,618 \\
0.135\end{array}$ & $\begin{array}{c}480,618 \\
0.153\end{array}$ & $\begin{array}{c}480,618 \\
0.138\end{array}$ & $\begin{array}{c}302,653 \\
0.056\end{array}$ & $\begin{array}{c}302,653 \\
0.034\end{array}$ \\
\hline & \multicolumn{6}{|c|}{ Panel B. Number of genders } \\
\hline NG & $\begin{array}{c}-0.018^{* * *} \\
{[0.005]}\end{array}$ & $\begin{array}{c}-0.023^{* * *} \\
{[0.005]}\end{array}$ & $\begin{array}{c}-1.00^{* * *} \\
{[0.22]}\end{array}$ & $\begin{array}{c}-0.708^{* * *} \\
{[0.193]}\end{array}$ & $\begin{array}{c}-0.51^{* * *} \\
{[0.16]}\end{array}$ & $\begin{array}{c}-0.252^{*} \\
{[0.136]}\end{array}$ \\
\hline \multirow[t]{2}{*}{$\mathrm{R}^{2}$} & $\begin{array}{c}480,618 \\
0.132\end{array}$ & $\begin{array}{c}480,618 \\
0.135\end{array}$ & $\begin{array}{c}480,618 \\
0.154\end{array}$ & $\begin{array}{c}480,618 \\
0.138\end{array}$ & $\begin{array}{c}302,653 \\
0.056\end{array}$ & $\begin{array}{c}302,653 \\
0.034\end{array}$ \\
\hline & \multicolumn{6}{|c|}{ Panel C. Gender assignment } \\
\hline GA & $\begin{array}{c}-0.011^{* *} \\
{[0.005]}\end{array}$ & $\begin{array}{c}-0.017^{* * *} \\
{[0.005]}\end{array}$ & $\begin{array}{c}-0.69^{* * *} \\
{[0.25]}\end{array}$ & $\begin{array}{c}-0.468^{* *} \\
{[0.219]}\end{array}$ & $\begin{array}{c}-0.51^{* * *} \\
{[0.18]}\end{array}$ & $\begin{array}{c}-0.335^{* *} \\
{[0.155]}\end{array}$ \\
\hline \multirow[t]{2}{*}{$\mathrm{R}^{2}$} & $\begin{array}{c}480,618 \\
0.132\end{array}$ & $\begin{array}{c}480,618 \\
0.135\end{array}$ & $\begin{array}{c}480,618 \\
0.153\end{array}$ & $\begin{array}{c}480,618 \\
0.138\end{array}$ & $\begin{array}{c}302,653 \\
0.056\end{array}$ & $\begin{array}{c}302,653 \\
0.034\end{array}$ \\
\hline & \multicolumn{6}{|c|}{ Panel D. Gender pronouns } \\
\hline GP & $\begin{array}{c}-0.019 * * \\
{[0.009]}\end{array}$ & $\begin{array}{l}-0.013 \\
{[0.009]}\end{array}$ & $\begin{array}{l}-0.44 \\
{[0.42]}\end{array}$ & $\begin{array}{c}-0.965 * * * \\
{[0.353]}\end{array}$ & $\begin{array}{c}0.12 \\
{[0.31]}\end{array}$ & $\begin{array}{c}-0.849^{* * *} \\
{[0.275]}\end{array}$ \\
\hline \multirow[t]{2}{*}{$\mathrm{R}^{2}$} & $\begin{array}{c}478,883 \\
0.132\end{array}$ & $\begin{array}{c}478,883 \\
0.135\end{array}$ & $\begin{array}{c}478,883 \\
0.153\end{array}$ & $\begin{array}{c}478,883 \\
0.138\end{array}$ & $\begin{array}{c}301,386 \\
0.056\end{array}$ & $\begin{array}{c}301,386 \\
0.034\end{array}$ \\
\hline & \multicolumn{6}{|c|}{ Panel E. Intensity } \\
\hline Intensity & $\begin{array}{c}-0.010^{* * *} \\
{[0.003]}\end{array}$ & $\begin{array}{c}-0.012^{* * *} \\
{[0.003]}\end{array}$ & $\begin{array}{c}-0.51^{* * *} \\
{[0.12]}\end{array}$ & $\begin{array}{c}-0.416^{* * *} \\
{[0.105]}\end{array}$ & $\begin{array}{c}-0.26^{* * *} \\
{[0.09]}\end{array}$ & $\begin{array}{c}-0.222^{* * *} \\
{[0.076]}\end{array}$ \\
\hline $\begin{array}{l}\text { Observations } \\
\mathrm{R}^{2}\end{array}$ & $\begin{array}{c}478,883 \\
0.132\end{array}$ & $\begin{array}{c}478,883 \\
0.135\end{array}$ & $\begin{array}{c}478,883 \\
0.153\end{array}$ & $\begin{array}{c}478,883 \\
0.138\end{array}$ & $\begin{array}{c}301,386 \\
0.056\end{array}$ & $\begin{array}{c}301,386 \\
0.034\end{array}$ \\
\hline $\begin{array}{l}\text { Respondent char. } \\
\text { Household char. } \\
\text { Respondent COB FE }\end{array}$ & $\begin{array}{l}\text { Yes } \\
\text { Yes } \\
\text { Yes }\end{array}$ & $\begin{array}{l}\text { Yes } \\
\text { Yes } \\
\text { Yes }\end{array}$ & $\begin{array}{l}\text { Yes } \\
\text { Yes } \\
\text { Yes }\end{array}$ & $\begin{array}{l}\text { Yes } \\
\text { Yes } \\
\text { Yes }\end{array}$ & $\begin{array}{l}\text { Yes } \\
\text { Yes } \\
\text { Yes }\end{array}$ & $\begin{array}{l}\text { Yes } \\
\text { Yes } \\
\text { Yes }\end{array}$ \\
\hline Mean & 0.60 & 0.55 & 27.2 & 22.51 & 44.2 & 36.57 \\
\hline
\end{tabular}

Table 7 notes: The estimates are computed using sample weights (PERWT) provided in the ACS (Ruggles et al. 2015). See appendix A for details on variable sources and definitions.

*** Significant at the 1 percent level. ${ }^{* *}$ Significant at the 5 percent level. ${ }^{*}$ Significant at the 10 percent level 
Columns (1) and (2) of Table 7 show the results for two measures of the extensive margin: labor force participation and an indicator for being employed, respectively. We obtain quantitatively and statistically comparable results for both measures when using our main language variable, SB, which confirms our previous analysis. Regarding the intensive margin, we also use the number of weeks worked and hours worked as dependent variables, including zeros in columns (3) and (4), and excluding zeros in columns (5) and (6). This provides various measures for whether language influences not only whether women work, but also how much. The impact of language is stronger for the extensive margin than for the intensive margin. For instance, although the impact of language is not precisely estimated when the dependent variable is the number of weeks worked excluding zeros in column (5), the magnitude is very small as female immigrants with a gender-based language work on average one and a half day less per year. This corresponds to only half a percent of the sample mean. This suggests that language acts as a vehicle for traditional gender roles that tend to ascribe women to the household, and to exclude them from the labor market. Once they overcome such roles by participating in the labor force, the impact of language remains, although it is weaker. This is potentially due to gender norms that unevenly distribute the burden of household tasks even among couples where both partners work, decreasing the labor supply of those female workers (Hicks et al. 2015).

In panels B, C, and D of Table 7 , we replicate our analysis of panel A with each of the individual measures of gender marking discussed in Section 2.1. In all cases, we obtain consistent results: married female immigrants speaking a language with gender distinctions are less likely to work, and conditional on working, they are doing so less intensively - although the magnitude of the impact of language on the intensive margin is smaller than that on the extensive margin. Finally, panel E reports the results when using the composite index Intensity described in section 2.1. The results in column (1) show that in comparison to those speaking a gender marked language with the lowest intensity (Intensity $=0$ ), female immigrants speaking a language with the highest gender intensity (Intensity $=3$ ) are 3 percentage points less likely to be in the labor force. The results are similar when using alternative outcome variables. Moreover, the estimates are more precisely estimated than with the indicator variables for language structures. In Appendix Table C.7, we show that the results in panel $\mathrm{E}$ are not sensitive to the specification of the Intensity measure, as the results hold with four alternative specifications of the index.

Alternative samples Appendix table C.8 explores the robustness of our main results from column (5) of Table 3 to alternative samples ${ }^{26}$ We use a wider age window (15-59) for the sample in column (2). Results are similar to the baseline, suggesting that education and retirement decisions are not impacted by language in a systematic direction. In column (3), we check that identification is not driven by peculiar migrants by restricting the sample to respondents speaking a language that is indigenous to their country of birth, where we define a language as not indigenous to a country if it is not listed as a principal language spoken in a country in the Encyclopedia Britannica Book of the Year (2010, pp. 766-770). We also checked

\footnotetext{
${ }^{26}$ See Appendix $\overline{\text { A.1.2 }}$ for more details on how we constructed these subsamples.
} 
that the results are not driven by outliers, and robust to excluding respondents from countries with less than 100 observations - this is the case for 1,064 respondents - and respondents speaking a language that is spoken by less than 100 observations - this is the case for 86 respondents. The results are again similar. We run the baseline specification on other subsamples as well: we include English speaking immigrants in column (4), exclude Mexican immigrants in column (5), include all types of households in column (6), and exclude languages that have been imputed as indicated by the quality flag QULANGUAG in the ACS (Ruggles et al. 2015). The results are robust to these alternative samples.

Alternative functional forms We also undertook robustness checks concerning the empirical specification. In particular, we replicate in Appendix Table C.9 the main results in columns (1) and (5) of Table 3 using both a probit and logit model. The marginal estimates evaluated at the mean are remarkably consistent with the estimates obtained via the OLS linear probability models. We take this as evidence that the functional form is not critical 27

Respondents husbands' labor supply Another important robustness check concerns the impact of language on the labor supply of the respondents' husbands. It is important to rule out the possibility that we observe the same effects than for the female respondents, namely that sex-based language speaking husbands are less likely to engage in the labor force as well. This would indicate that our results are spurious and unrelated to traditional gender norms. To verify this, Appendix Table C.10 replicates columns (1), (2), and (5) of Table 3 , with the labor supply of the respondents' husbands as the dependent variable, and with their characteristics as controls. So that the sample is qualitatively similar to the one used in the baseline analysis, we exclude native husbands as well as English speaking husbands. We find a significant positive association between husbands' SB language variable and their labor force participation for the specifications without husband country of birth fixed effects. This suggests that our language variable captures traditional gender roles in that it leads couples to a traditional division of labor where wives stay home and husbands work. Yet, once we control for husband country of birth fixed effects, the association is no longer statistically significant, suggesting that the influence of this cultural trait is larger for women. Overall this analysis reassures us that our results are not driven by some correlated factor, which would lead speakers of sexbased language to decrease their labor market engagement regardless of their own gender.

Heterogeneity across marital status Finally, we also explore potential heterogeneity in the impact of language structure across marital status. Although married women represent $83 \%$ of the original uncorrected sample, it is worth analyzing whether the impact of language is similar for unmarried women. In Appendix Table C.11. we replicate column (5) of Table 3 with an additional indicator variable for unmarried respondents, as well as the interaction of this indicator with the SB variable. Depending on the specification, it

\footnotetext{
${ }^{27}$ We maintain the OLS throughout the paper, however, as it is computationally too intensive to run these models with the inclusion of hundreds of fixed effects in most of our specifications.
} 
reveals that unmarried women are 8 to 14 percentage points more likely to participate in the labor force compared to married women. Second, sex-based speakers are less likely than their counterparts to be in the labor force when they are married, but the reverse is true when they are unmarried: while married women speaking a sex-based language are 5 percentage points less likely to be in the labor force than their counterparts, unmarried women speaking a sex-based language are 8 percentage points more likely to work than their counterparts. When paired with the findings for single women in Hicks et al. (2015), this result suggests that some forms of gender roles may be "dormant" when unmarried - the pressure to not work, to raise children, to provide household goods - and that these forces may activate for married women but not be present for unmarried women. Other gender norms and choices, such as deciding how much time to devote to household chores such as cleaning, may be established earlier in life and may appear even in unmarried households (Hicks et al. 2015).

\section{Conclusion}

This paper contributes to the existing literature on the relationship between grammatical features of language and economic behavior by examining the behavior of immigrants, who travel with acquired cultural baggage, including their language. While no quasi-experimental study is likely to rule out all potential sources of endogeneity, our data driven, fixed effects, epidemiological analysis advances the existing frontier in the economic analysis of language and provides suggestive evidence that the study of language deserves further attention.

We provide support for the nascent strand of literature in which languages serve not only to reflect, but also possibly to reinforce and transmit culture. In particular, our quantitative exercise isolates the fraction of this association attributable to gendered language from the portion associated with other cultural and gender norms correlated with language. We find that about two thirds of the correlation between language and labor market outcomes can be attributed to the latter, while at most one third can be attributed to the direct impact of language structure or other time-variant cultural forces not captured by traditional observables or by the wide array of additional checks we employ. Whether by altering preference formation or by perpetuating inefficient social norms, language and other social constructs clearly have the potential to hinder economic development and stymie progress of gender equality.

We frame our analysis within a collective household labor supply model and demonstrate that language has a direct effect that is not strongly influenced by either husband characteristics or the distribution of bargaining power within the household. This suggests that language, and more broadly acquired gender norms, should be considered in their own right in analyses of female labor force participation. In this regard, language is especially promising since it allows researchers to study a cultural trait which is observable, quantifiable, and varies at the individual level.

Furthermore, we show that the labor market associations with language are larger in magnitude than 
some factors traditionally considered to capture bargaining power, in line with Oreffice (2014) who finds that culture can mediate the relationship between bargaining power and the labor supply. Indeed, our findings regarding the impact of language in linguistically homogeneous and heterogeneous households suggests that the impact of one's own language is the most robust predictor of behavior, although the spouse's language is also associated with a partner's decision making.

Finally, recognizing that language is a network technology allows us to examine the role that ethnic enclaves play in influencing female labor force participation. In theory, enclaves may improve labor market outcomes by providing information about formal jobs and reducing social stigma on employment. At the same time, enclaves are likely to provide isolation from U.S. norms and to reinforce gender norms that languages capture, enhancing the impact of gender in language. We present evidence suggesting that the latter effect is present. Explaining the role of language within social networks, therefore may shed new light on how networks may impose not only benefits but also costs on its members by reinforcing cultural norms.

Our results have important implications for policy. Specifically, programs designed to promote female labor force participation and immigrant assimilation could be more appropriately designed and targeted by recognizing the existence of stronger gender norms among subsets of speakers. Future research may consider experimental approaches to further analyze the impact of language on behavior, and in particular, to better understand the policy implications of movements for gender neutrality in language. Another interesting avenue for research might be to study the impact of gendered grammatical features in a marriage market framework as in Grossbard (2015), which studies intermarriage among immigrants along linguistic lines.

\section{References}

Adsera, A. \& Pytlikova, M. (2015), 'The role of language in shaping international migration', The Economic Journal 125(586), F49-F81.

Alesina, A., Giuliano, P. \& Nunn, N. (2013), 'On the origins of gender roles: women and the plough', The Quarterly Journal of Economics 128(2), pp. 469-530.

Aronow, P. M. \& Samii, C. (2016), 'Does regression produce representative estimates of causal effects?', American Journal of Political Science 60(1), 250-267.

Blau, F. D. \& Kahn, L. M. (2015), 'Substitution between individual and source country characteristics: Social capital, culture, and us labor market outcomes among immigrant women', Journal of Human Capital 9(4), pp. 439-482.

Blau, F., Kahn, L. \& Papps, K. (2011), 'Gender, source country characteristics, and labor market assimilation among immigrants', The Review of Economics and Statistics 93(1), pp. 43-58.

Blundell, R., Chiappori, P.-A., Magnac, T. \& Meghir, C. (2007), 'Collective labour supply: Heterogeneity and non-participation', The Review of Economic Studies 74(2), pp. 417-445. 
Chen, M. K. (2013), 'The effect of language on economic behavior: Evidence from savings rates, health behaviors, and retirement assets', American Economic Review 103(2), pp. 690-731.

Chiappori, P.-A., Fortin, B. \& Lacroix, G. (2002), 'Marriage market, divorce legislation, and household labor supply', Journal of Political Economy 110(1), pp. 37-72.

Davis, L. \& Reynolds, M. (2016), Gendered language and the educational gender gap. Available at SSRN: https://ssrn.com/abstract $=2782540$.

Dryer, M. \& Haspelmath, M. (2011), 'The world atlas of language structures online'.

Edin, P.-A., Fredriksson, P. \& Åslund, O. (2003), 'Ethnic enclaves and the economic success of immigrantsevidence from a natural experiment', The Quarterly Journal of Economics 118(1), 329-357.

Everett, C. (2013), Linguistic relativity: Evidence across languages and cognitive domains, Vol. 25, Walter de Gruyter.

Farré, L. \& Vella, F. (2013), 'The intergenerational transmission of gender role attitudes and its implications for female labour force participation', Economica 80(318), pp. 219-247.

Fernández, R. (2007), 'Alfred marshall lecture women, work, and culture', Journal of the European Economic Association 5(2-3), 305-332.

Fernández, R. (2011), Chapter 11 - does culture matter?, Vol. 1 of Handbook of social economics, Elsevier, pp. $481-510$.

Fernández, R. (2013), 'Cultural change as learning: The evolution of female labor force participation over a century', The American Economic Review 103(1), pp. 472-500.

Fernández, R. \& Fogli, A. (2009), 'Culture: An empirical investigation of beliefs, work, and fertility', American Economic Journal: Macroeconomics 1(1), pp. 146-177.

Field, E., Pande, R., Rigol, N., Schaner, S. \& Moore, C. T. (2016), On her account: Can strengthening women's financial control boost female labor supply?, Technical report.

Gay, V., Hicks, D. \& Santacreu-Vasut, E. (2016), Migration as a window into the coevolution between language and behavior, in S. Roberts, C. Cuskley, L. McCrohon, L. Barceló-Coblijn, O. Fehér \& T. Verhoef, eds, 'The evolution of language: Proceedings of the 11th international conference (EVOLANGX11)', Online at http://evolang.org/neworleans/papers/120.html.

Gay, V., Santacreu-Vasut, E. \& Shoham, A. (2013), The grammatical origins of gender roles, Technical report.

Givati, Y. \& Troiano, U. (2012), 'Law, economics, and culture: Theory of mandated benefits and evidence from maternity leave policies', Journal of Law and Economics 55(2), pp. 339-364.

Goldin, C. (2014), 'A grand gender convergence: Its last chapter', The American Economic Review 104(4), pp. 1091-1119.

Grossbard, S. (2015), The marriage motive: A price theory of marriage. How marriage markets affect employment, consumption and savings., Springer.

Hicks, D. L., Santacreu-Vasut, E. \& Shoham, A. (2015), 'Does mother tongue make for women's work? lin- 
guistics, household labor, and gender identity', Journal of Economic Behavior E Organization 110, pp. $19-44$.

Inc., E. B. (2010), 2010 Britannica book of the year, Vol. 35, Encyclopaedia britannica.

Ladd, D. R., Roberts, S. G. \& Dediu, D. (2015), 'Correlational studies in typological and historical linguistics', Annu. Rev. Linguist. 1(1), pp. 221-241.

Lundberg, S. J., Pollak, R. A. \& Wales, T. J. (1997), 'Do husbands and wives pool their resources? evidence from the united kingdom child benefit', The Journal of Human Resources 32.3, pp. 463-480.

Lupyan, G. \& Dale, R. (2010), 'Language structure is partly determined by social structure', PloS one 5(1).

Mavisakalyan, A. (2015), 'Gender in language and gender in employment', Oxford Development Studies 43(4), pp. 403-424.

Mavisakalyan, A. \& Weber, C. (2016), Linguistic relativity and economics, Technical report.

Munshi, K. (2003), 'Networks in the modern economy: Mexican migrants in the us labor market', The Quarterly Journal of Economics 118(2), 549-599.

Oreffice, S. (2014), 'Culture and household decision making. balance of power and labor supply choices of us-born and foreign-born couples', Journal of Labor Research 35(2), pp. 162-184.

Oreffice, S. \& Quintana-Domeque, C. (2012), 'Fat spouses and hours of work: are body and pareto weights correlated?', IZA Journal of Labor Economics 1(1), 6.

Roberts, S. G., Winters, J. \& Chen, K. (2015), 'Future tense and economic decisions: controlling for cultural evolution', PloS one 10(7).

Roberts, S. \& Winters, J. (2013), 'Linguistic diversity and traffic accidents: Lessons from statistical studies of cultural traits', PloS one $\mathbf{8}(8)$.

Ruggles, S., Genadek, K., Goeken, R., Grover, J. \& Sobek, M. (2015), Integrated public use microdata series: Version 6.0.

Santacreu-Vasut, E., Shenkar, O. \& Shoham, A. (2014), 'Linguistic gender marking and its international business ramifications', Journal of International Business Studies 45(9), pp. 1170-1178.

Santacreu-Vasut, E., Shoham, A. \& Gay, V. (2013), 'Do female/male distinctions in language matter? evidence from gender political quotas', Applied Economics Letters 20(5), pp. 495-498.

Spolaore, E. \& Wacziarg, R. (2009), 'The diffusion of development', The Quarterly Journal of Economics 124(2), pp. 469-529.

Spolaore, E. \& Wacziarg, R. (2016), Ancestry and development: New evidence.

van der Velde, L., Tyrowicz, J. \& Siwinska, J. (2015), 'Language and (the estimates of) the gender wage gap', Economics Letters 136, pp. 165-170. 